International Journal of Language Education

Volume 5, Number 4, 2021, pp. 309-323

ISSN: $2548-8457$ (Print) 2548-8465 (Online)

Doi: https://doi.org/10.26858/ijole.v5i4.19701

\title{
A phenomenological diagnosis of the ProDuct-based Instruction in EFL's writing class: Barriers and strategies to tackle
}

\author{
Piyawan Rungwaraphong \\ Prince of Songkla University, Thailand \\ Email:bewandjack@hotmail.co.nz
}

Received: 18 March 2021

Reviewed: 1 August 2021-30 October 2021

Accepted: 5 December 2021

\begin{abstract}
This paper presents a phenomenological diagnosis of the implementation of ProDuct-based Instruction (PDI) in EFL's writing class in Thailand contexts. PDI is a new instructional method for teaching business English writing. Its key is in the products that are tangible and appeal to human senses; the product's tangibility serves as a scaffold to help students generate ideas and stimulate analysis and interrogations. The study focused on the first phase of PDI, in which students were required to learn inductively, and was conducted to explore barriers that both the learners and the instructors encounter while learning inductively in the researcher's PDI approach, and to discover possible solutions to tackle with those barriers. Participants were 3 Thai lecturers of English writing and 60 Thai students from three government universities in Thailand. Data was collected through vignettes, participant observations, and students' written texts. Results indicate three major barriers of implementing inductive phase of PDI in Thailand contexts, which include: students' English reading and grammar skills; students' inference skill; and teachers' inductive teaching expertise. The study suggests solutions to tackle these barriers, which include creating a guided graphic organizer, providing formative assessment and feedback for the students, and organizing a PDI training for the teachers who want to adopt PDI in their profession.
\end{abstract}

Keywords: EFL; inductive; instruction; tangible; writing.

\section{Introduction}

In the year 2020, Rungwaraphong (2020a) invented a new instructional method for teaching business English writing, called ProDuct-based Instruction or PDI. Its key is in the products that are tangible and appeal to human senses: the product's tangibility serves as a scaffold to help students generate ideas and stimulate analysis and interrogations. This new instructional approach underpins inductive inference and the rationale that underlies inductive instruction is that the deductive learning approach is instructor-driven and emphasizes on memorizing, and therefore should be replaced with a student-driven and discovery of knowledge through experience. The product which is picked to use in English writing class should be accessible to learners, promotes hands-on experiences, encourages exploration and reflection, and provides learners with tools to think with. In PDI classes, abstract, complicated business writing genres or concepts are concretely represented through concrete, touchable, seeable, or edible products. 
The lecturers who adopt PDI as their instructional method link writing activities or assignments to authentic business contexts, bridging the gap between writing in academic contexts and writing in real business contexts. PDI activities or assignments require students to explore in the real business context. Writing classes that follow PDI principles will contextualize learning activities and give value for a chance provided for students to produce writing pieces based on information elicited from the real context.

As PDI is a newly invented teaching methodology, it is still under researched. The study by Rungwaraphong (2020a) investigated the dichotomy between PDI and the other conventional teaching method, and found some difficulties that the learners will have to deal with when engaging in PDI. However, the study did not explained in details about the problems and did not provide solutions to tackle the difficulties. In addition, little is known about how Thai students experience and understand inductive learning. The current study, therefore, set out to fill in this gap. It was an attempt to find out about Thai learners' and lecturers' experiences of inductive ProDuct-based Instruction at the tertiary level. The design of the current research drew on a phenomenological study in which the lived experiences of Thai learners and lecturers in relation to inductive ProDuct-based Instruction were explored.

\section{Literature review}

\section{ProDuct-based Instruction - PDI}

ProDuct-based Instruction or PDI was developed on the premise that a person develops certain skills from experiential and situated activities, which doesn't have to take place within the boundaries of classroom. According to Rungwaraphong (2020a), PDI involves the inductive theory, and the tangibility and authenticity of the learning medium. The basis for the PDI is to use the tangibility of a product to gear students to think and to interrogate among their peers. PDI requires the students to initiate their own learning, with the assistance of the teacher; rules or principles of the target language is not taught, but examples in which those rules or principles exist are given to them. The students interrogate among themselves, helping each other to see patterns or styles of the target language that prevalently appear in all the examples given, before formulating those identified patterns or styles as the rules. The study by Rungwaraphong (2020a) has explained PDI process and compared it with the conventional Paper-based Instruction (PPI). Figure 1 illustrates Rungwaraphong's comparison of procedures and learning activities in PPI \& PDI modules. As show in the figure, PDI and PPI mainly comprises of 8 steps starting from inductive-based learning activities in Step 1-3. The divergence of both instructional methods is in Step 4 onwards, in which the sources of information for students to write about are different. While students in PPI method are provided with information needed for writing a product description, the PDI method requires students to select their own product and carry out product analysis. 


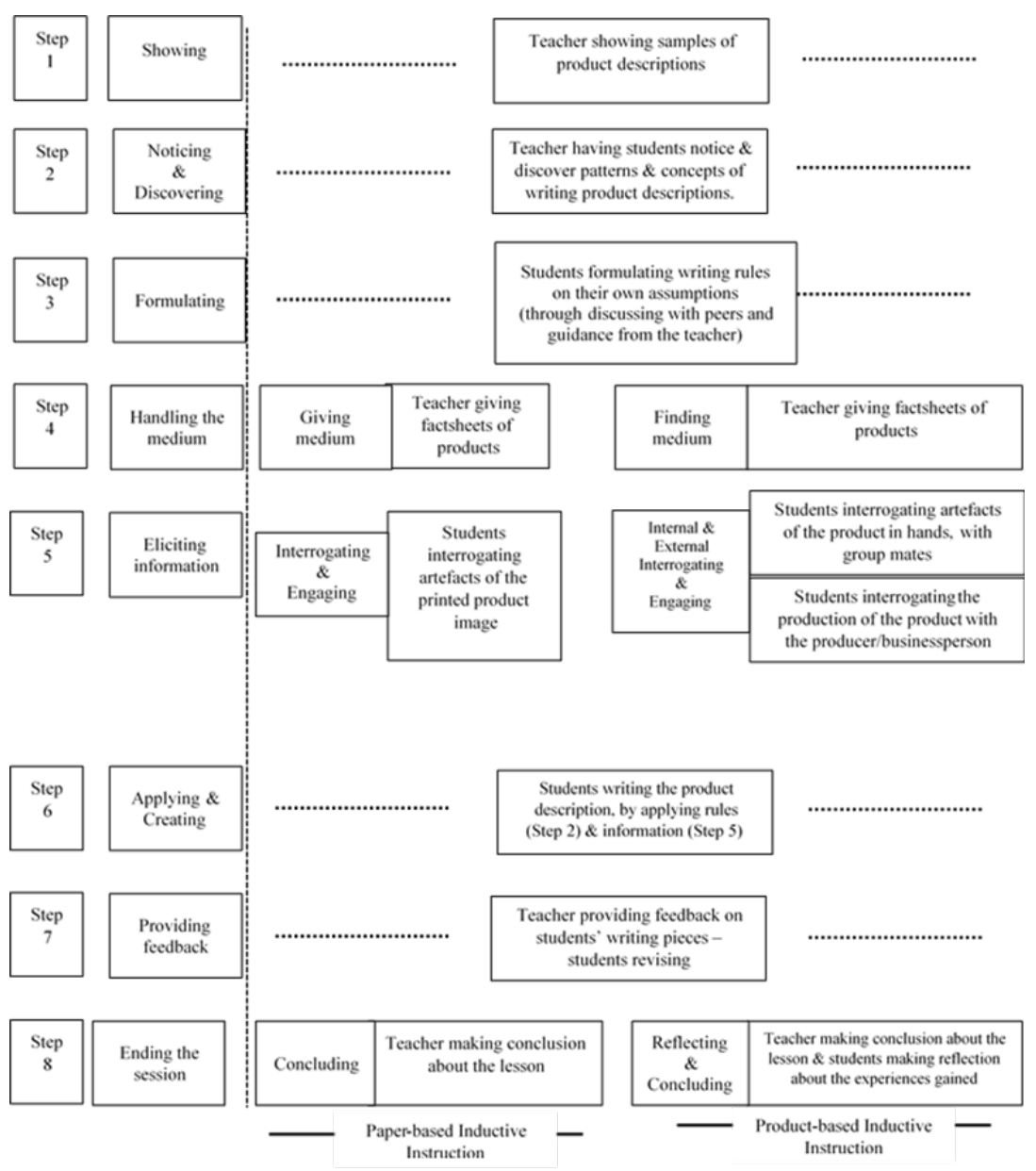

Figure1. Rungwaraphong's comparison of PPI \& PDI modules

Results of Rungwaraphong's (2020a) study confirmed that the PDI as an inductive approach is effective in improving Thai students' writing skills, and it inspires Thai students to write in English. Apart from that, PDI seems to be able to reduce the boredom of Paper-based Instruction (PPI). Findings of the study further indicates Thai learners encounter some difficulties while engaging in PDI activities, particularly in the first three steps which are the inductive phase.

Inductive reasoning

Inductive Reasoning is interchangeably called induction. It is often defined as the opposite to the deductive reasoning. The deductive reasoning starts out from a theory and ends with the confirmation while the inductive reasoning works the other way around -it begins with the observation and ends with building a theory. Broad definitions of inductive reasoning have been given. Tomic (1995), for example, defines inductive reasoning as a form of human thinking skills or thinking processes in which a person makes generalization from the given "instances, examples, or observations in order to find a description that applies to them all” (p. 484). Hofstadter (2001) regards inductive reasoning as the ability to draw relations through the detection of regularities. In the inductive process, a person will "detect regularities, rules, or generalizations" from numerous examples (Klauer, Willmes, \& Phye, 2002, p.1). The role of inductive reasoning is underlined by Perret (2015), who regards inductive reasoning as the core function of children's cognitive development as inductive processes play a major role in solving both complex and familiar 
problems and thus serve as a central means of intelligence development in the children. Inductive reasoning is a human cognitive activity which involves three fundamental mechanisms: detecting regularities, extracting relations, and concluding general rules. In this light, the generalization will occur when the person can identify the properties or characters that are commonly shared across the given examples. Godwin and Fisher (2015) highlight the generalization as the milestone feature of inductive reasoning; it is a powerful tool for generating new knowledge. Human beings create new knowledge on the basis of what is known. Like Perret (2015), Godwin and Fisher regard the ability to make such an induction as a sign of mature cognition.

Inductive reasoning in language education

The difference between inductive and deductive reasoning when applied to the teaching of language are in the lesson procedures, learner roles, and teacher roles. The language teaching will be deductive when the instructor teaches or explains an explicit content of rules or theories, which the students apply to examples. According to Ahmadzai, Katawazai, and Sandaran (2019), deductive teaching approach is more teacher-centered and top-down, meaning that the teacher starts with presenting and explaining the students a grammar rule, and the student learn the rule through practice and produce their own examples. Inductive teaching approach, in contrast, processes from the bottom, meaning that the teacher presenting the examples which can be in the forms of a text, audio or visual in a context, and learners then work on the given resources to discover the rules themselves. Mallia (2014) believes that the inductive teaching approach is more student-centered as the students take greater responsibility in their own learning. The teacher role in this teaching approach is to carefully select the materials that can efficiently illustrate the use of the target language. The degree to which the students can detect and discover the rules or the grammar of the target language depends on the degree of guidance from the teacher. Mallia's assertion of inductive approach in language teaching points out the importance of the teacher's guidance and the fundamental mechanisms of inductive reasoning include observation, detection, and generalization. Rungwaraphong (2020a) similarly suggests that rather than showing students the example of the writing pieces in the writing course and having students identify writing rules and patterns, the teacher might need to provide worksheets that are purposefully planned and designed to help them easily discover and formulating the writing rules on their own in an ample time. The well-planed and designed worksheets serve as the map for the students and the preparation of such learning map implies the essential, supportive roles of teachers in the inductive instruction. When provided with sufficient assisting materials, students do not feel they are left alone and lost during the inductive procedures.

\section{Purpose of the study}

The purpose of the current study is to understand Thai EFL students' and instructors' experience of inductive instruction when implemented in business English writing classes. Specifically, the study aimed to explore barriers related to implementing PDI in business English writing classes, and to discover possible solutions to tackle with the identified barriers. In this regard, the study aims to answer two research questions:

1. What are barriers that Thai students and instructors encountered when PDI was implemented in English writing classes?

2. How can those identified barriers be overcome? 


\section{Methodological Framework}

Research setting and procedure

The current study was set in three business English writing training cohorts. All these three writing cohorts were organized by the researcher. Each training cohort had one trainer and 20 student trainees, making 60 student trainees in total. The training specifically trained the student trainees to write a product description. The trainers were Thai instructors of business English writing from three different government universities in Thailand. One month before the training began, all three of them had been required to attend an informal PDI training organized by the researcher. The PDI training for lecturers was two days and about the inductive procedures of teaching English writing as well as the principles and implementation of ProDuct-based Instruction. All the materials that were used in the student training were prepared by the researcher. The training cohorts were organized at three different universities in Thailand and the student trainees were volunteers. Each training cohort were 3-hour a day and organized four-days in a row at each trainer's university. The activities in the 4-day training was adapted from Rungwaraphong's (2020a) PDI, and can be graphically demonstrated as follow.
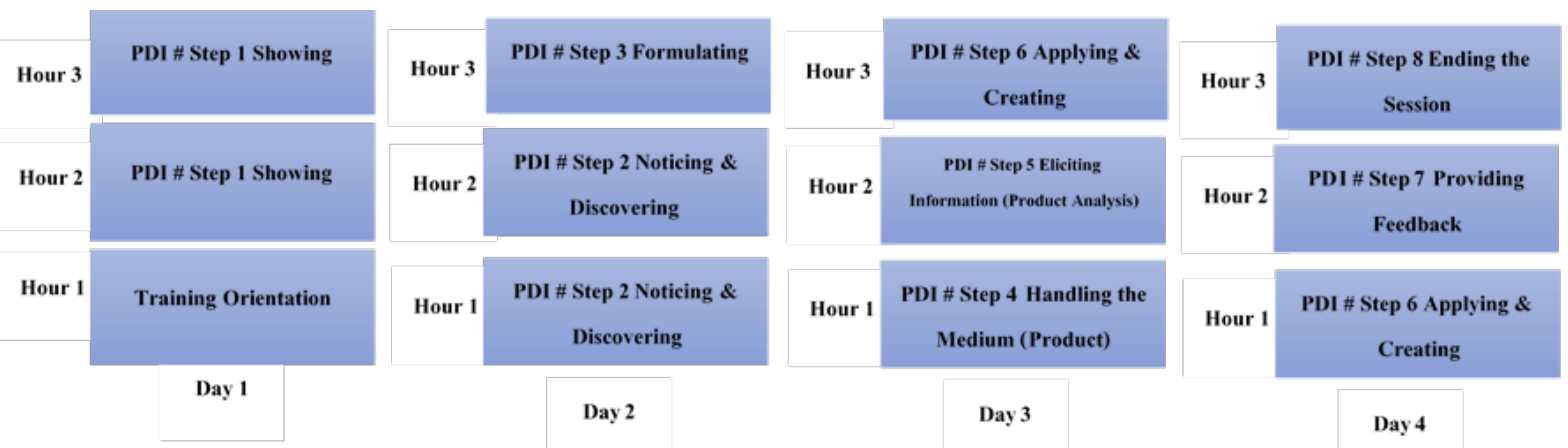

Figure 2. PDI training procedure

According to Figure 2, the training took four days and lasted 3 hours a day. In each training cohort, the students were divided into five groups; 4 students per group. The trainer began the training on Day 1 with giving a one-hour orientation to the students, giving an overview of the training as well as explaining the purpose, policies, rules, and the expectations of the training to the students. In Hours 2- 3, the trainer began the first step of inductive instruction by showing samples of product descriptions to the students. On Day 2, the students began the process of noticing and identifying the patterns that commonly existed in all the samples given. In the last hour of Day 2, the students started to formulate the rules and principles of writing product description. Day 3 was the milestone of PDI; the students were given real products in which they were required to write a description. The students started analyzing the given products, following PDI principles which focused on human's five senses: sight, sound, smell, taste, and touch. The product's manufacturing information, including the producer's information were also given. In Hour 3 of Day 3 each group started to write the product description using the rules and principles that they had formulated on their own on Day 2. They had another more hour to finish and polish their product description in Hour 1 of Day 4. After that, the students handed in their product description to the trainer; there were 5 product descriptions from each cohort and the trainer needed to do a quick assessment before giving the feedback to every group in Hour 2 of Day 4. The last hour of Day 4 was for concluding and ending the training. 
Research design

In order to describe the essence of inductive PDI approach and determine what happens in actual practice of PDI teaching approach when implemented in business English writing classes, the current study adopted a phenomenological study. Phenomenology is commonly described as the study of a phenomena, emphasizing the lived experiences of people involved in that phenomena. Lester (1999) described phenomenological study as an approach to gain deep information through various qualitative methods. It places an emphasis on personal perception and interpretation of the phenomena- a phenomena is described through the perspectives of people who experience it. Despite the fact that the phenomenology is regarded as a qualitative design, not all qualitative data collection methods are suited to the design. According to Finlay (2013), narratives in interviews, diaries and protocols, participant observation, and researcher's own introspective accounts are the most common methods that are more suited to the phenomelogy. In the current study, the implementation of PDI as an inductive instructional method in business writing training cohorts is regarded as a phenomena, and the description of this phenomena was achieved through perspectives of teacher trainers and the students participating in these training.

\section{Participants}

Sixty students from all three writing training cohorts and three Thai instructors who taught in the training took part in the current study. The students aged between 20-22 years old, and were English majors. Haft of them were male and the other half were female. The instructors were all female and aged 32, 38, and 41. All three of them were Thai; 2 of them received bachelor degrees in Arts majoring English while the other one got bachelor degree in Education. All three of them hold master degrees; two in Language Education and the other one in Arts, all from Thai universities.

\section{Data collection and analysis}

Data of the study were collected from both student and instructor participants using three data collection methods

\section{Vignettes}

In the current study the vignette technique was employed to tap the lecturer and the student participants' personal opinions and comments to their experiences of learning and teaching inductively. Skilling and Stylianides (2019) described vignette as an instrument for collecting data that are particularly related to "value-laden constructs" such as a person's belief or attitudes which influence the person's practice. In educational research, vignette enables researchers to gain insights into interpretations and concerns that the participants may have about a phenomena, leading to a deep understanding of the phenomena. When using vignettes, the researcher presents a scenario or a short story that is written and aligned with the real situation to encourage the participants to discuss or express their opinions (Jeffries \& Maeder, 2004-2005, p. 18). According to Neale (1999), vignettes are appropriate for exploring sensitive topics which participants might not feel comfortable to discuss. When eliciting narratives from the participants, the researcher will empathize the participant's situation; the researcher may offer further prompts in order to gear the participants to elaborate further dimensions of the situation.

In the current study vignettes were conducted after participant observations were completed. They were used to elicit the instructors' and the students' understanding and perceptions of inductive PDI. The adequate number of vignettes is not set in stone (Bachmann et 
al., 2008). Johnson and Orme (1996) suggested that the maximum number of vignettes is twenty while the maximum number of attributes in a vignette is eight. Following these guideline, the current study carried out vignettes with three lecturer trainers, and ten students from each training cohorts were randomly recruited to respond the vignettes. Eight different stories were presented to each of the respondents and they were asked to respond the stories. They were also encouraged to use their personal experiences to clarify their responses. Each vignette investigates the inductive attribute identified in Rungwaraphong's (2020a) PDI instructional procedure, making eight attributes investigated through the vignette method. The stories given to the respondents were written in the third person and placed the respondent into the position of the character(s). Vignettes for the student and the lecturer respondents are the same; however, the questions were slightly different. The questions presented in the vignettes is the mixture of both closed and open questions. Below are the example a vignette and students and lecturers' questions.

\begin{tabular}{|c|c|}
\hline $\begin{array}{l}\text { Malee, a Thai student majoring marketing, has registere } \\
\text { She is in Year 4, and going the graduate very soon. Sh } \\
\text { bad so she want to improve her English particularly } \\
\text { inductive instructional approach. In her first class sess } \\
\text { product. Following inductive approach, the Mrs. Bett } \\
\text { description written in English. Malee and her classmate } \\
\text { they have to do is to read and identify writing patterns tl }\end{array}$ & $\begin{array}{l}\text { he course English for Business, offered in her university } \\
\text { takes this course because she knows her English is quite } \\
\text { iting skill. In this course Mrs. Betty, the lecturer, uses } \\
\text { n, Mrs. Betty wants students to write a description of a } \\
\text { gives the students numerous examples of real product } \\
\text { are randomly grouped into a group of } 4 \text {. The first thing } \\
\text { thave found in all the sample product descriptions. }\end{array}$ \\
\hline Students' Questions & Lecturers' Questions \\
\hline $\begin{array}{l}\text { 1. Please give examples of what might be going } \\
\text { through Malee's mind. } \\
\text { 2. If you were Malee, what difficulties that you think } \\
\text { you will encounter in this situation. } \\
\text { 3. If you encounter those difficulties, what will you do? } \\
\text { 4. What do you like or don't like about the learning } \\
\text { activity presented in this scenario? }\end{array}$ & $\begin{array}{l}\text { 1. Please give examples of what might be going } \\
\text { through Malee's mind. } \\
\text { 2. If you were Mrs. Betty, what difficulties that you, as } \\
\text { a lecturer, think you will encounter in this situation. } \\
\text { 3. What would you do to cope with those difficultlies? } \\
\text { 4. What do you like or don't like about the learning } \\
\text { activity presented in this scenario? }\end{array}$ \\
\hline
\end{tabular}

Figure 3. Example of students' and lecturers vignette

\section{Participant observation}

In the current study, participant observation was conducted to gain insights and deeper understanding of things that were taking place in the inductive writing cohorts. In addition, the participant observation was expected to uncover unanticipated opportunities to explore in further details; information from the observation were used as the data baseline for the construction of the vignette scenarios. Frey (2018) points that participant observation allows researchers to gain rich and authentic data on people and environment in a particular context, as through this method the researchers immerse themselves in a community or an event. In the current study, the researcher immersed in the training cohorts to observe activities and participants' actions while they engaged 
in the inductive process. Two participant observations were conducted in each training cohort, making 6 participant observations in total for the whole research.

\section{Students' written texts}

Student participants from each cohort, in a group of 4, were asked to produce a description of product. Their written texts were used for error analysis following Rungwaraphong's (2020a) writing assessment rubrics. Table 1 illustrates Rungwaraphong's criteria for assessing the product description.

Table 1. Rubrics for assessing the product description assignment

\begin{tabular}{|c|c|c|c|}
\hline Components & Score & Level & Indicators \\
\hline \multirow[t]{4}{*}{ Content } & 4 & Excellent & $\begin{array}{l}\text { Present sufficient well-chosen information and features that } \\
\text { focus on the product's benefits and enable the reader to easily } \\
\text { identify what the product is within the title. }\end{array}$ \\
\hline & 3 & Good & $\begin{array}{l}\text { Present information and features about the product that partly } \\
\text { focus on the product's benefits and reflect the product }\end{array}$ \\
\hline & 2 & Fair & $\begin{array}{l}\text { Present some information and features about the product, } \\
\text { which make it hard for the reader to identify the product and } \\
\text { perceive the benefits of the product }\end{array}$ \\
\hline & 1 & Poor & $\begin{array}{l}\text { Present no clear information and do not include sufficient } \\
\text { features of the product }\end{array}$ \\
\hline \multirow[t]{4}{*}{ Vocabulary } & 4 & Excellent & $\begin{array}{l}\text { Use powerful words that sell; vocabulary choses focus on } \\
\text { benefits and results }\end{array}$ \\
\hline & 3 & Good & $\begin{array}{l}\text { Use words used that are not much powerful; and contain some } \\
\text { errors in vocabulary but not interfere with understanding }\end{array}$ \\
\hline & 2 & Fair & $\begin{array}{l}\text { Words used are dull and contain some errors sometimes in } \\
\text { vocabulary that sometimes interfere with understanding }\end{array}$ \\
\hline & 1 & Poor & $\begin{array}{l}\text { Contain many errors in vocabulary choices, which severely } \\
\text { interfere with understanding }\end{array}$ \\
\hline \multirow[t]{4}{*}{ Grammar } & 4 & Excellent & Good in grammar, no errors in grammar \\
\hline & 3 & Good & $\begin{array}{l}\text { Contain errors in grammar but do not interfere with } \\
\text { understanding }\end{array}$ \\
\hline & 2 & Fair & $\begin{array}{l}\text { Contain errors in grammar that slightly interfere with } \\
\text { understanding }\end{array}$ \\
\hline & 1 & Poor & $\begin{array}{l}\text { Contain errors in grammar that severely interfere with } \\
\text { understanding }\end{array}$ \\
\hline \multirow[t]{4}{*}{ Visual Appeal } & 4 & Excellent & $\begin{array}{l}\text { Include clear and appealing images that provide multiple angel } \\
\text { of the product so that the reader are induced to read the } \\
\text { description of the product }\end{array}$ \\
\hline & 3 & Good & $\begin{array}{l}\text { Include images of the product, but not provide multiple angel } \\
\text { of the product }\end{array}$ \\
\hline & 2 & Fair & Include some images of the product \\
\hline & 1 & Poor & Do not have any image of the product \\
\hline \multirow[t]{3}{*}{ Organization } & 4 & Excellent & $\begin{array}{l}\text { The product's specs or features are well structured in } \\
\text { paragraphs and bullet lists in a way that engages the reader's } \\
\text { emotion }\end{array}$ \\
\hline & 3 & Good & $\begin{array}{l}\text { The product's specs or features are well structured in } \\
\text { paragraphs and bullet lists, but not much engages the reader's } \\
\text { emotion. }\end{array}$ \\
\hline & 2 & Fair & $\begin{array}{l}\text { The product's specs or features are slightly scattered } \\
\text { throughout the writing }\end{array}$ \\
\hline
\end{tabular}


1 Poor The product's specs or features are fairly scattered throughout the writing, which looks confusing for the reader

The rubric was used to assess the participants' product descriptions in five essential elements. The identifications of errors that appears in the participants' written texts and the classifications into its type were useful for the researcher in determining the effectiveness of the inductive inference that the student participants conducted on their own, as well as in reflecting the areas of inductive instruction which should be placed greater emphasis or requires revisions in the future practice.

\section{Result and discussion}

Students' PDI writing performance

Product descriptions written by the students from each training cohorts were collected and crossed examined. There were 15 groups of students from three cohorts, and thus 15 product descriptions total. The product descriptions were assessed in five essential elements following the rubric discussed in the previous section. Results of the assessment were illustrated in Table 2.

Table 2. Students' writing results

\begin{tabular}{|c|c|c|c|c|c|c|c|}
\hline \multirow{2}{*}{$\begin{array}{c}\text { Group } \\
\text { No. }\end{array}$} & \multicolumn{5}{|c|}{ Assessment Components } & \multirow{2}{*}{$\begin{array}{c}\text { Avg. } \\
\text { Score } \\
\text { (4) }\end{array}$} & \multirow{2}{*}{$\begin{array}{l}\text { Avg. } \\
\text { Label }\end{array}$} \\
\hline & $\begin{array}{c}\text { Content } \\
(4)\end{array}$ & $\begin{array}{c}\text { Vocabulary } \\
(4)\end{array}$ & $\begin{array}{c}\text { Grammar } \\
(4)\end{array}$ & $\begin{array}{c}\text { Visual } \\
\text { Appeal(4) }\end{array}$ & $\begin{array}{c}\text { Organization } \\
(4)\end{array}$ & & \\
\hline 1. & 3 & 3 & 2 & 3 & 2 & 2.6 & Fair \\
\hline 2. & 3 & 3 & 2 & 3 & 2 & 2.6 & Fair \\
\hline 3. & 4 & 4 & 3 & 3 & 2 & 3.2 & Good \\
\hline 4. & 2 & 3 & 1 & 3 & 1 & 2.0 & Fair \\
\hline 5. & 3 & 4 & 2 & 4 & 2 & 3.0 & Good \\
\hline 6. & 4 & 3 & 1 & 4 & 2 & 2.8 & Fair \\
\hline 7. & 2 & 2 & 2 & 3 & 1 & 2.0 & Fair \\
\hline 8. & 1 & 2 & 2 & 4 & 1 & 2.0 & Fair \\
\hline 9. & 3 & 4 & 2 & 3 & 2 & 2.8 & Fair \\
\hline 10. & 3 & 4 & 3 & 3 & 1 & 2.8 & Fair \\
\hline 11. & 3 & 3 & 1 & 2 & 2 & 2.2 & Fair \\
\hline 12. & 2 & 2 & 2 & 3 & 1 & 2.0 & Fair \\
\hline 13. & 4 & 3 & 2 & 4 & 2 & 3.0 & Good \\
\hline 14. & 1 & 2 & 1 & 3 & 1 & 1.6 & Poor \\
\hline 15. & 3 & 3 & 2 & 3 & 2 & 2.6 & Fair \\
\hline Avg. & 3.27 & 3.0 & 1.87 & 3.2 & 1.6 & & \\
\hline $\begin{array}{l}\text { Avg. } \\
\text { Label }\end{array}$ & Good & Good & Poor & Good & Poor & & \\
\hline
\end{tabular}

Table 2 illustrates that among the five elements of product descriptions that have been assessed, grammar and organization of the students' writing received the lowest scores (1.87 and 1.6, respectively); these two elements were identified as poor while the other four elements were labeled good. 


\section{Barriers of PDI practice}

Data from participant observations, responses from the vignettes, and cross examinations of participants' written texts indicate three major barriers of the implementation of inductive PDI in EFL's writing classes in Thailand.

\section{Students' English reading}

Students' and lecturer trainers' responses from the vignettes indicated that the primary factor that make inductive learning difficult for the students is students' own English reading skills. The students pointed that reading English texts is difficult for them, this is not to mention when they had to read in order to, not just to comprehend the texts or the stories, scrutinize the style and structure of the writing. This finding points that in inductive teaching of writing, the skills needed for the students is not just writing; students' ability to read critically turns out to be equally significant for this instructional method to be successful. The finding about difficulties in reading English among Thai students is not new. According to Rungwaraphong (2020b), Thai students struggle with many reading problems in the classroom. One of the problems is their ability to interpret new words; not knowing the meaning of new words or misinterpreting them impairs students' potentiality to comprehend the given texts. This implies that their ability to read critically- to scrutinize the style and structure of the text given may be also impaired. In PDI instruction, the reading speed is significantly important as the students are given just a few hours to perform the inductive process (Step 1-3 in Figure 2). If this very first step of inductive PDI fails, the students cannot resume the remaining steps, suggesting that the students might not be able to achieve the required writing task. The feeling of overwhelmed with information was also identified as another difficult feature of inductive learning. The students explained that they were given "too many examples of good product description", but in the first place they "cannot read them all" within a limit of time. Some of their group mates may be able to read all the examples but they still felt "the data they obtained are too much". The feeling overwhelmed by the volume of information was to the point at which students felt more confused than well-informed about the topic of product description. Most of the students indicated that they could have coped with the very first three steps of inductive learning if they had had some helping tools such as worksheets or concept maps, which they could use to guide their reading and handling with the samples of product descriptions.

\section{Students' inference skill}

Findings of the current study indicate that the students' inference skill is another challenge of inductive PDI approach. In the absence of teacher-provided worksheets or concept maps of Business English Writing, students reported that they felt unconfident with the writing rules that they inferred and formulated. Their uncertainty of their inference was clearly shown in their writing performance, which was found to contain numerous errors particularly in terms of grammar and writing organization. This finding implies that Thai students' inference skill becomes another area that need to be improved, and that the adoption of inductive instruction in Thailand's EFL writing class is not guaranteed to generate correct business English writing. The score associated with writing organization as indicated in Table 2 seems to imply that the students may not be able to detect the patterns of writing that commonly exist in all the given samples. Murphy and Ross (2010) explained that human beings, when having to make inferences with no information for guidance, will make inferences based on their knowledge about the object; that is, they tend to put the object into the same category of the object that they are familiar with, or the 
one that they see share many common properties. The induction like this one is a category-based, generalizing from the known to the unknown and may lead to the incorrect overgeneralization, which does not guarantee to generate correct knowledge. This reminds Harriman's (2008) statement that thinking is unlike perception as it can be fallible. Even though human beings have logic, which enables them to make an assumption, it comes with no guarantee that the logic is applied correctly. Importantly, grammar of the students' writing, which was also identified as Poor in Table 2, indicates that the inductive instruction may not be an effective strategy for teaching grammars for Thai students. Even though a number of researchers support the implicit grammar teaching, a number of studies indicate that when it comes to EFL contexts, the explicit teaching tend to be more practical and easier for learners to learn grammar as it make the lessons clearer: the rules are taught and students do not have to discover $t$ the rules by themselves (Rungwaraphong, 2020a). The fact that human thinking is a fallible process gives rise to the precaution for cognitive errors (or cognitive biases) during the process of Formulation (Step 3 in PDI). This means the assumption that the students made from their inductive learning in Step 1-3 in PDI can be fallible. Chances are that the students may try to interpret the given evidences in ways that match their expectations or existing beliefs. Nickerson (1998) regards such an interpretation as the "confirmation bias", which occurs when one tries to understand an evidence in a way that is consonant with his or her preexisting beliefs, expectations, or a hypothesis in hand.

\section{Teachers' inductive teaching expertise}

Data from the vignettes and participant observations point that the trainers in the current study lack decent expertise in teaching inductively. This is partly due to the fact that PDI is a new method that has been just invented and not yet well-known. The teachers who were invited to be the trainers attended only a 2-day training, which organized by the researcher just a month before the research project took place. All three of the teacher trainers explained during the vignettes that they did not quite understand the theories underlying PDI and felt unconfident in implementing each step of PDI procedures. This is consonant with what had been observed in the training cohorts: when students struggled with the process of noticing and formulating writing rules, the teacher trainers did not know how to help students. It seems they do not understand their roles as an inductive teacher. This finding gives rise to the awareness that when a new teaching method is implemented in a class, the teacher's understanding to the backbone of that new teaching method as well as his or her teaching expertise are significant. The teacher's subject expertise alone does not guarantee that he or she will successfully implement that new teaching method. All the three lecturers gave similar comments on the given vignette scenarios; their responses to the situations reflect that they are not able to resolve the problems that presented in the scenarios. When asked why they could not provide solutions to the given situations, all three lecturers admitted that their repertoire of ways to handling the tasks of teaching was limited; this affected their decision to choose and apply what is appropriate. All three trainers received master degrees relevant to English language, but not specifically in English language teaching. Apart from this, the fact that teaching in tertiary level in Thailand does not require formal teaching qualifications may help explain this finding. As a teacher certificate is not a legal requirement to teach in tertiary level in Thailand, this makes a call for the expansion for teachers' pedagogical knowledge specifically about PDI, and give rise to the provision of in-service training for lecturers who aim to adopt PDI in their profession. 
Tackling the barriers

Despite the aforementioned difficulties that exist during the process of inductive inference, the analysis of the participants' responses to vignettes as well as information from the observations reflects possible strategies for tackling the barriers that exist in PDI. The following are things that should be done to minimize the barriers identified in the PDI's implementation.

\section{Creating a guided graphic organizer}

Students' responses on vignettes indicate that the students needed some guiding tools to help them manage information, organize ideas and clench essential concepts during the very first steps of inductive PDI; the majority of the students' participants explained that they felt lost and had no clue of where to start, what to observe, how much observation was enough, and when to begin the formulation of the writing rules. Most of them felt overwhelmed and indicated that if they had been given some helping tools, they could have done better in inductively observing and discovering common patterns that existed in the given product description samples. The teacher participants gave an opinion on this point; they suggested that during the first three steps of inductive discovery and formulation of writing rules, the teachers might have to provide the students with a graphic organizer that will guide their thinking, and shape their observation and discovery, step-by-step. Bearing the need for some guiding graphic organizers in mind, the current study calls for the opportunity for the lecturers to take an active role in developing a guided graphic organizer that is more student-centered and emphasizes students' self-discovery and formulation of accurate knowledge. In addition to a graphic organizer to assist students to manage the information, students also need to be provided with supplementary worksheets on grammar. Such grammar worksheets may be given as homework assignments or self-study exercises; these supplementary grammar worksheets aim to help students practice and improve their grammar skills. The grammar to be practiced need to emphasize the forms and functions that are prevalently used in the writing of product descriptions. However, what forms and functions of grammar that are prevalently used in product descriptions is beyond the scope of the current study and therefore need to be further investigated.

\section{Providing formative assessment and feedback}

One of the problems of PDI as found in the current study is the accuracy of students' inference which later on impacted their formulation of rules and their writing performance. Even though the goal of the implementation of PDI in English writing classes is to enable students to learn inductively, it cannot be refused that linguistic accuracy is also the goal of language education. Responses from vignettes with all three participant lecturers suggest that the PDI approach does not give sufficient, reflective feedback for the students to assess their performance. In the PDI approach, there is only one assessment conducted on the students' writing performance at the end of the process and there is no feedback provided for students along the way either for their assumption of rules or their writing performance. It can be said that feedback given in the PDI is rather summative. This calls for the provision of formative feedback, in which students are given opportunities to receive ongoing feedback that highlight the areas that are wrong and the students can correct it before getting it assessed, rather than writing one writing piece and get it assessed with no chance to rehearse and revise (Dekker,2018). On top of all, while the summative feedback is still important at the end of the learning process the provision of formative assessment also need to take place in order to provide ongoing feedback that students can improve their writing performance, which later on increase the final scores of their writing pieces. According to 
Sutherland (2017), teachers should routinely provide formative information to students and monitor student comprehension, so that support can be timely provided to the students during the course delivery. Apart from benefiting the students, the formative feedback is useful for teachers as it can help them identify their own strengths as well as areas that need further improvements. This information will guide the teacher for further instruction and preparation for the course activities in the future.

\section{Training the teacher}

In Thailand, teaching certification or licensure to teach in government schools is required for both Thai-natives and non-Thai teachers; however, teaching licensure is not required for Thai native lecturers in tertiary level. In addition, the fact that PDI is a new instructional method and Thai lecturers might not be familiar with its procedures calls for the provision for in-service training for lecturers who want to adopt PDI in their teaching. This is because a successful implementation of a new teaching concept or approach is dependent upon the lecturers. In this respect, as Day (1999) directly claims, teachers are "the greatest asset"; the success of a school is dependent upon "successful teacher development" (p. 2). The in-service training serves as the mechanism that prepare the lecturers to cope with changes that have occurred in the teaching. The training need to keep the lecturers up to date on the most current pedagogical concepts and practices. As for PDI in particular, lecturers in Thailand's higher education might have decent general pedagogical knowledge, but not specifically for PDI approach. PDI trainings should specifically give Thai lecturers the fundamental knowledge of PDI as well as serve as a platform for them to practice teaching inductively.

\section{Conclusion and recommendation}

In the current study vignettes were used, as a complementary technique alongside participant observations and students' writing tasks, to explore Thai lecturers' and students' perception of inductive PDI approach in business English writing course. Findings of the current study indicate that both lecturers and students were struggling with the first three steps of the inductive instruction. The difficulties reported by the participants resulted from their unclear understanding and limited experience with PDI, which reflect in the students' final writing outcomes- their product descriptions contains numerous errors particularly in terms of grammar and writing organization. This implies that incorrect conclusions may be drawn during the process of inductive discovery by the students, giving rise to the need for the instructor to ensure that the students have strong foundation or understanding of principles of writing product descriptions in the very beginning of the writing process. Apart from this, there is a need for the provision of formative feedback, so that students can gain constant feedback on their writing progress on a timely-basis. Recommendations for tackling the aforementioned barriers include providing the students with a graphic organizer, which will serve as a scaffolding tool that will guide them and enrich their understanding of the provided examples and new concepts. Some sorts of trainings are necessary for both the lecturers and the students. While the students may need to be specifically trained about critical reading skills, the lecturers, likewise, also need to be specifically trained about the practices of PDI. Even though graphic organizers are highly recommended for use in PDI classes, how such the graphic organizers should be like -a concept map, chart or any formsis beyond the scope of the current study and therefore need to be further researched. There is also a need to investigate how a PDI in-service training should be organized for the lecturers, as well as how critical English reading and grammar skills of Thai EFL students can be improved. 
Declaration of conflicting interest

The authors declare that there is no conflict of interest in this work.

Funding acknowledgement

The author received no financial support for the research, authorship, and/or publication of this article.

\section{References}

Ahmadzai, S., Katawazai, R., \& Sandaran, S.C. (2019). The use of deductive and inductive approaches in teaching grammar for Afghan University students of English and Literature Studies. International Journal of Engineering and Advanced Technology, 8(5), 1230-1235.

Bachmann, L. M. et al. (2008). Vignette studies of medical choice and judgement to study caregivers' medical decision behaviour: systematic review. BMC medical research methodology, 8(1), p. 50.

Day, C. (1999). Developing teachers: The challenges of lifelong learning. London: RoutledgeFalmer.

Dekker, K. (2018). Effective learning methods: The importance of formative feedback. Retrieved from https://www.studiosity.com/blog/effective-learning-methods-theimportance-of-formative-feedback

Finlay, L. (2013). Unfolding the phenomenological research process: Iterative stages of "seeing afresh". Journal of Humanistic Psychology, 53(2), 172-201.

Frey, B.B. (2018). Participant observation. Retrieved from https://methods.sagepub.com/reference/the-sage- encyclopedia-of-educational-researchmeasurement-and-evaluation/i15505.xml

Harriman, D. (2008). Errors in inductive reasoning. Retrieved from https://theobjectivestandard.com/2008/11/inductive-reasoning/

Jeffries, C., \& Maeder, D. W. (2004-2005). Using vignettes to build and assess teacher understanding of instructional strategies. The Professional Educator, 27(1-2), 17-28. Retrieved from http://files.eric.ed.gov/fulltext/EJ728478.pdf

Johnson, R. M. \& Orme, B. K. (1996). How many questions should I ask in choice-based conjoint studies. Sawtooth Software Research Papers.

Godwin, K. E., \& Fisher, A. V. (2015). Inductive generalization with familiar categories: Developmental changes in children's reliance on perceptual similarity and kind information. Frontiers in Psychology, 6, Article 897.

Hofstadter, D. R. (2001). Epilogue: Analogy as the core of cognition. In D. Gentner, K. J. Holyoak, \& B.N. Kokinov (Eds.), The analogical mind: Perspectives from cognitive science (pp. 499-538). Cambridge, MA: Massachusetts Institute of Technology Press.

Klauer, K., Willmes, K. \& Phye, G. (2002). Inducing inductive reasoning: does it transfer to fluid intelligence? Contemporary Educational Psychology, 27(1), 1-25.

Lester, S. (1999). An introduction to phenomenological research. Stan Lester Developments, Taunton.

Mallia, J.G. (2014). Inductive and deductive approaches to teaching English grammar. Arab World English Journal, 5(2), 221-235.

Murphy, G. L., \& Ross, B. H. (2010). Uncertainty in category-based induction: When do 
people integrate across categories? Journal of Experimental Psychology: Learning, Memory, and Cognition, 36(2), 263-276.

Neale, B. (1999). Post Divorce Childhoods. Retrieved from http://www.leeds.ac.uk/family

Nickerson, R. S. (1998). Confirmation bias: A ubiquitous phenomenon in many guises. Review of General Psychology, 2(2), 175-220.

Perret, P. (2015). Children's inductive reasoning: Developmental and educational perspectives. Journal of Cognitive Education and Psychology, Journal of Cognitive Education and Psychology, 14(3), 389 - 408.

Rungwaraphong, P. (2020a). The implementation of inductive teaching approaches in business English writing in an EFL context: Paper-based and product-based instructions. Manuscript submitted for publication.

Rungwaraphong, P. (2020b). Using glosses for vocabulary assistance in Thai EFL reading classes: An investigation of preferences, effective types, and elements. Electronic Journal of Foreign Language Teaching, 17(1), 301-317.

Skilling, K. \& Stylianides, G.J. (2019). Using vignettes in educational research: a framework for vignette construction. International Journal of Research \& Method in Education, 1-16.

Sutherland, C.M. (2017). Formative feedback for teaching and learning effectiveness. Retrieved from https://explorance.com/blog/formative-feedback-for-teaching-andlearning-effectiveness/

Tomic, W. (1995). Training in inductive reasoning and problem solving. Contemporary Educational Psychology. The Open University, Heerlen, The Netherlands. 20(1), 483-490. 